\title{
Two years of Springer-IJM association
}

It was in January 2007 that Indian Journal of Microbiology came into focus of Springer India Pvt. Ltd. Since then IJM has undergone many significant changes starting from online submission of articles, improvement in printing quality and amendment of Editorial Board. Over the past 2 years the journal has become fully operational through SpringerLink (www.springer.com/12088) leading to its visibility by showing substantial rise in its readership and increase in the numbers of manuscript that have been submitted. Full text download on the Springer portal has increased. Earlier many articles were queued up for publication, now processing of papers is streamlined. Many new editors have been included and more than 250 reviewers have been embraced to fasten up the process of reviewing. Not only this, Springer India Pvt. Ltd. has taken initiative to establish the Indian Journal of Microbiology in International arena. Regular issues on special themes including bioremediation and biodiversity, genomics \& metagenomics were brought out. The quality of research articles submitted to the Journal has improved substantially and many authors from abroad have published their research/review articles in this reputed journal. Although still not deemed for Pubmed and Medline, all efforts are being made to bring this journal under this preview.

We still need to work harder to enter among the international ranking of Journals and bring several improvements in the coming years. Through this editorial I seek the support of all those who are associated with AMI and IJM. I would request our editors and reviewers to pay more effort than before in order to bring out publication of the good peer reviewed articles. This is the time to review our progress and to launch some new initiatives.

Editor-in-Chief Prof. Rup Lal 